\title{
Enhancing excitability of dopamine neurons promotes motivational behaviour through increased action initiation
}

\author{
Linde Boekhoudt ${ }^{a}$, Ellen C. Wijbrans ${ }^{a}$, Jodie H.K. Man ${ }^{a}$, \\ Mieneke C.M. Luijendijk ${ }^{a}$, Johannes W. de Jong ${ }^{a, b}$, \\ Geoffrey van der Plasse ${ }^{a}$, Louk J.M.J. Vanderschuren ${ }^{c}$, \\ Roger A.H. Adan ${ }^{a}$ *
}

\author{
${ }^{a}$ Brain Center Rudolf Magnus, Department of Translational Neuroscience, University Medical Centre \\ Utrecht, Universiteitsweg 100, 3585 CG Utrecht, The Netherlands \\ ${ }^{\mathrm{b}}$ Department of Molecular and Cell Biology, University of California, Berkeley, CA, USA \\ 'Department of Animals in Science and Society, Division of Behavioural Neuroscience, Faculty of \\ Veterinary Medicine, Utrecht University, Utrecht, The Netherlands
}

Received 24 February 2017; received in revised form 28 August 2017; accepted 3 November 2017

\author{
KEYWORDS \\ Dopamine; \\ Motivation; \\ DREADD; \\ TH-Cre rats; \\ Ventral tegmental \\ area; \\ Substantia nigra
}

\begin{abstract}
Motivational deficits are a key symptom in multiple psychiatric disorders, including major depressive disorder, schizophrenia and addiction. A likely neural substrate for these motivational deficits is the brain dopamine (DA) system. In particular, DA signalling in the nucleus accumbens, which originates from DA neurons in the ventral tegmental area (VTA), has been identified as a crucial substrate for effort-related and activational aspects of motivation. Unravelling how VTA DA neuronal activity relates to motivational behaviours is required to understand how motivational deficits in psychiatry can be specifically targeted. In this study, we therefore used designer receptors exclusively activated by designer drugs (DREADD) in TH:Cre rats, in order to determine the effects of chemogenetic DA neuron activation on different aspects of motivational behaviour. We found that chemogenetic activation of DA neurons in the VTA, but not substantia nigra, significantly increased responding for sucrose under a progressive ratio schedule of reinforcement. More specifically, high effort exertion was characterized by increased initiations of reward-seeking actions. This effect was dependent on effort
\end{abstract}

*Corresponding author.

E-mail address: r.a.h.adan@umcutrecht.nl (R.A.H. Adan). 
requirements and instrumental contingencies, but was not affected by sucrose pre-feeding. Together, these findings indicate that VTA DA neuronal activation drives motivational behaviour by facilitating action initiation. With this study, we show that enhancing excitability of VTA DA neurons is a viable strategy to improve motivational behaviour.

(c) 2017 Elsevier B.V. and ECNP. All rights reserved.

\section{Introduction}

Motivational processes regulate the drive to overcome costs and exert effort in order to obtain a desired goal. Conversely, deficits in motivation are a key symptom of multiple psychiatric disorders, including major depressive disorder, schizophrenia and addiction, which strongly interfere with functional outcome and quality of life (Fervaha et al., 2016, 2015; Robinson and Berridge, 1993; Wise, 2004). In order to successfully treat motivational deficits in psychiatric disorders, it is essential to better understand the neurobiological substrates underlying distinct aspects of motivational behaviour. It has been hypothesized that motivational deficits observed in psychiatric disorders may arise from alterations in dopamine (DA) neuronal activity (Maia and Frank, 2016; Whitton et al., 2015). Although the brain DA system has been widely implicated in regulating motivation (Berridge, 2007; Salamone and Correa, 2012; Wise, 2004), the exact relationship between midbrain DA neuronal activity and motivational behaviour remains incompletely understood.

DA signalling in the nucleus accumbens (NAC), originating from VTA DA neurons, has been identified as a crucial substrate for motivational behaviour (Nunes et al., 2013; Salamone and Correa, 2012). Thus, blockade of NAc DA neurotransmission strongly diminished responding for rewards under a progressive ratio (PR) schedule of reinforcement in rodents (Aberman et al., 1998; Aberman and Salamone, 1999; Bari and Pierce, 2005), whilst enhancing NAc DA signalling increased motivational behaviour (Peciña et al., 2003; Trifilieff et al., 2013). We have previously shown that enhanced activity of VTA mesolimbic neurons increased the motivation for sucrose in rats (Boender et al., 2014; de Jong et al., 2015). However, it has been suggested that also the nigrostriatal DA pathway, from SNc towards dorsal striatum, may play an important role in motivational processes (Ikemoto et al., 2015; Palmiter, 2008; Wise, 2009). For example, both VTA and SNc DA neurons display reward prediction errors (Barter et al., 2015; Schultz et al., 1997), and mice have been shown to self-administer optogenetic stimulation of DA neurons in VTA as well as SNc, suggesting that activation of either of these neuronal populations is sufficient to reinforce behaviour (Ilango et al., 2014; Rossi et al., 2013). However, direct evidence for a role of SNc DA neuron activity in driving motivational behaviour is lacking. In this study, we directly compared the effects of chemogenetic activation of DA neurons in the VTA or SNc on motivational behaviour, using designer receptors exclusively activated by designer drugs (DREADD) technology in TH:Cre transgenic rats.

In addition, it remains unknown which aspects of motivation are affected by VTA DA neuronal activity that drive the increase in responding. Mesolimbic DA is thought to be particularly involved in effort-related and activational aspects of motivational behaviour (Salamone et al., 2016a; Salamone and Correa, 2012). For example, DA depletion selectively impairs instrumental behaviour under high effort requirements (Aberman and Salamone, 1999). Recently, it was observed that phasic DA transients in the NAc were associated with the initiation of actions as well as the level of effort performed within these actions (Ko and Wanat, 2016). In the present study, we therefore investigated which aspects of motivational behaviour were affected by chemogenetic activation of DA neurons. Chemogenetic activation of DA neurons enhances the excitability of VTA DA neurons (Boekhoudt et al., 2016). We hypothesized that this stimulates the initiation of rewardseeking actions, promoting the animal to engage in motivational behaviour. We tested this by examining whether the DA-induced increase in responding was dependent on prior access to the reinforcer, presence of the reinforcer, effort requirement, and action-outcome contingencies.

\section{Experimental procedures}

\subsection{Subjects}

In total, 49 male rats were used for the experiments. TH:Cre transgenic rats (Witten et al., 2011) were bred in-house, by crossing heterozygous $\mathrm{TH}: \mathrm{Cre}^{+/-}\left(\mathrm{Cre}^{+}\right)$rats with wild type Long Evans mates. TH:Cre ${ }^{-1-}\left(\mathrm{Cre}^{-}\right)$littermates were used for control groups. Animals were socially housed with ad libitum access to regular chow and water in their home cage, and were kept on a reversed 12-hour light-dark schedule (lights off 7:00). All experiments were performed in accordance with Dutch laws (Wet op Dierproeven, 1996) and European regulations (Guideline 86/609/EEC), and were approved by the Animal Experiments Committee of Utrecht University.

\subsection{Surgical procedures}

Experiments were conducted as described previously (Boender et al., 2014). In brief, rats were injected bilaterally with AAV2.5hSyn-DIO-hM3D(Gq)-mCherry (1.0-7.6*E12 molecules/ml) purchased from UNC Vector Core. Rats were allocated to one of three experimental groups: 1) VTA:D(Gq) $+: \mathrm{Cre}^{+}$rats injected with the DREADD virus into the VTA; 2) SN:D(Gq)+: $\mathrm{Cre}^{+}$rats injected with the DREADD virus into the SNc; and 3) Cre-: $\mathrm{Cre}^{-}$rats injected with the DREADD virus into either the VTA or SNc (control group). Perioperative care and anaesthesia were performed as described previously (Boender et al., 2014). There was a minimum of seven weeks in between surgery and behavioural testing. All behavioural experiments were carried out in adult rats.

Experiments were performed in four cohorts. Injection coordinates were adjusted to the rats' body weight (BW) during surgery. The first group $\left(\mathrm{n}=6 \mathrm{Cre}^{+}+6 \mathrm{Cre}^{-}\right.$, mean BW $\left.482 \mathrm{~g}\right)$ received viral injections into the VTA: AP $-5.8, M L+1.3\left(5^{\circ}\right.$ angle $)$, DV -8.4 ; 
$1.5 \mu \mathrm{l}$ per hemisphere. The second group $\left(\mathrm{n}=7 \mathrm{Cre}^{+}+5 \mathrm{Cre}^{-}\right.$, mean BW $327 \mathrm{~g}$ ) received injections into the SNc: AP $-5.4, \mathrm{ML}$ +2.2, DV -7.7; $1 \mu \mathrm{l}$ per hemisphere. The third group $(\mathrm{n}=19$, mean BW $143 \mathrm{~g})$ was injected into either the VTA $\left(\mathrm{n}=6 \mathrm{Cre}^{+}\right.$and $6 \mathrm{Cre}^{-}$; $\mathrm{AP}-5.4, \mathrm{ML}+1.1\left(5^{\circ}\right.$ angle), $\left.\mathrm{DV}-7.4\right)$, or $\mathrm{SNc}\left(\mathrm{n}=6 \mathrm{Cre}^{+} ; \mathrm{AP}-5.2\right.$, $M L+2.0\left(5^{\circ}\right.$ angle), DV 7.0). The fourth group $\left(n=8 \mathrm{Cre}^{+}\right.$, mean BW $334 \mathrm{~g})$ received injections into the VTA (AP $-5.6, \mathrm{ML}+1.3\left(5^{\circ}\right.$ angle), DV -8.2), $1 \mu$ l per hemisphere. All coordinates are in $\mathrm{mm}$ relative to Bregma.

\subsection{Drugs}

The DREADD ligand clozapine-N-oxide (CNO; kindly provided by Bryan Roth (University of North Carolina, Chapel Hill NC, USA) and the NIMH Chemical Synthesis and Drug Supply Program) was dissolved in sterile saline $(0.9 \% \mathrm{NaCl})$, using $30-60 \mathrm{~min}$ of sonification (until no precipitate formed). For all experiments, a dose of $0.3 \mathrm{mg} / \mathrm{kg}$ CNO was used. This dose was based on previous work (Boekhoudt et al., 2016, 2014) and a pilot dose-response study. Dissolved CNO was kept at $4{ }^{\circ} \mathrm{C}$ in between injections, for a maximum of four weeks. All injections were given intra-peritoneally (i.p.) at $1 \mathrm{ml}$ per $\mathrm{kg}$ bodyweight.

\subsection{Behavioural apparatus and testing}

Experiments were conducted as described previously (Boender et al. 2014; de Jong et al., 2015; la Fleur et al., 2007). Rats were trained and tested in twelve sound-attenuated and ventilated operant conditioning chambers $\left(30.5^{*} 24.22 * 1.0 \mathrm{~cm}\right.$; MedAssociates, Georgia, VT, USA), equipped with two retractable levers, a cue light above each lever, and a food receptacle in between the levers. Following habituation and shaping sessions, rats were first trained to lever press for sucrose pellets under fixed ratio 1 (FR1) schedule of reinforcement, during which a single lever press on the active lever (ALP) resulted in reward delivery. Presses on the inactive lever (ILP) were recorded, but had no programmed consequences. Completion of a ratio resulted in retraction of both levers, presentation of the cue light above the active lever, and delivery of a sucrose pellet into the food receptacle. In general, all sucrose pellets were consumed, even after pre-feeding. Following a $20 \mathrm{~s}$ time-out (inter-trial interval), the cue light went off, and the levers were presented again. Position of the active lever (left/right) was counter-balanced between animals. When rats had successfully acquired performance under the FR1 contingency, a PR schedule of reinforcement (first three cohorts) or FR5 schedule of reinforcement (fourth cohort) was introduced. Under the PR schedule, ratio requirements were progressively increased following each reward $(n=1,2,4,9,12,15,20,25$, etc.) (Richardson and Roberts, 1996). PR sessions ended when the animal had not received a reward for $30 \mathrm{~min}$. FR5 sessions lasted for $30 \mathrm{~min}$. Primary readouts for instrumental performance were total number of ALP and ILP. In addition, the total number of rewards obtained and breakpoint (i.e. the highest number of lever presses that an animal made for a single reward within a session) were assessed for performance under a PR schedule; these parameters are directly related to the number of ALP. Furthermore, the percentage ILP was calculated (ILP/[ALP+ILP] $\left.{ }^{*} 100 \%\right)$, in order to compare ILP across different levels of ALP.

When all rats showed stable performance under the PR or FR5 schedule (i.e., earning $n \pm 1$ rewards on three consecutive days), the testing phase started. CNO or saline was administered 30 min before onset of the task and treatment order was counter-balanced between animals, with at least $24 \mathrm{~h}$ between tests. For sucrose pre-feeding sessions, the rats were allowed to free-feed on sucrose pellets (identical to those earned in the instrumental task) for $60 \mathrm{~min}$, in a separate cage, before starting the instrumental task as usual. Prior to testing, the rats were habituated to the sucrose freefeeding set-up, to ensure that they would consume the pellets. Also in these experiments, $\mathrm{CNO}$ or saline was administered 30 min prior to task onset, i.e. $30 \mathrm{~min}$ after initial exposure to sucrose free-feeding. Before testing the effects of $\mathrm{CNO}$ treatment on responding in extinction, rats were subjected to three extinction training sessions, in order to minimize potential learning effects between the two consecutive testing days. PR responding with reversed lever contingencies was tested in the third experimental cohort only. In this group, rats were re-trained on the PR schedule for three days following extinction, during which they reached their previous PR baseline performance. During the two reversal sessions, the active and inactive levers were reversed compared to all prior sessions. Thus, in order to receive a sucrose pellet, rats had to press the former inactive lever. The contingency was reversed only once, and did not change during the reversal sessions. To avoid an interaction of CNO treatment with learning effects, all rats received CNO on the first day of reversal. On the following day, all rats were treated with saline.

Cohorts 1, 2 and 3 were used for testing under PR schedule (both in non-pre-fed and pre-fed conditions) and in extinction. Cohort 3 was used for reversal testing. Cohort 4 was used for testing under FR5 schedule, both in non-pre-fed and pre-fed conditions.

To assess the effects of enhanced DA neuronal activity on lever press patterns during performance of the PR schedule, ALP were divided into separate bouts. A "bout" was defined as one or more lever presses, at least 2 seconds separated from adjacent bouts, based on the study of Ko and Wanat (2016). For each ratio requirement of the PR task, the following parameters were calculated: number of ALP bouts, average number of ALP within a bout (total ALP/number of bouts), bout interval (time between consecutive bouts), time to complete ratio, lever press rate (total $\mathrm{ALP} /$ time to complete ratio).

\subsection{Tissue preparation and immunohistochemistry}

DREADD expression was analysed as described previously (Boekhoudt et al., 2017, 2016). In brief, rats were euthanized using a lethal dose of pentobarbital, followed by perfusion with $4 \%$ paraformaldehyde (PFA) in phosphate-buffered saline (PBS). Sucrose-saturated brain tissue was sliced at $40 \mu \mathrm{m}$, and stained for $\mathrm{hM} 3 \mathrm{D}(\mathrm{Gq})$-mCherry and tyrosine hydroxylase (TH) using primary antibodies Rabbit anti-dsRed (Clontech) and Mouse anti-TH (Millipore), respectively, and secondary antibodies Goat anti-Rabbit Alexa 568 (Abcam) and Goat antimouse Alexa 488 (Abcam). Fluorescence was analysed using a Zeiss Axioscope A1 microscope and Axiovision software. Confocal pictures (20x magnification) were taken with a Olympus Fluoview 1000 microscope and FluoView software. Image processing and cell counts were performed with ImageJ.

DREADD expression was evaluated in all rats. In total, two rats (one VTA:D $(G q)+$ rat and one SN:D(Gq) + rat) were excluded from behavioural analysis because of poor DREADD expression. Quantification of co-localisation of DREADD and TH was carried out in VTA:D $(G q)+$ and $S N: D(G q)+$ rats ( $n=3$ per group), in targeted regions, i.e. VTA or SNc between -5.2 and $-6.0 \mathrm{~mm}$ from Bregma (4-6 slices per animal).

\subsection{Statistical analysis}

Statistical tests were performed in SPSS 16.0. Since behavioural effects of CNO treatment compared to saline did not differ between experimental cohorts, the data were pooled for analysis. Normal distribution of the data was assessed using Kolmogorov-Smirnov test and $\mathrm{Q}-\mathrm{Q}$ plots. Number of ALP and ILP were transformed by natural log and square root, respectively, to allow for parametric testing. A repeated measures general linear model (RM-GLM) was used to test effects of Group (Cre-/VTA:D(Gq)+/SN:D(Gq)+) and Treatment (saline/CNO). When a significant Group*Treatment interaction was found, LSD post hoc tests were carried out to test treatment effects 
A
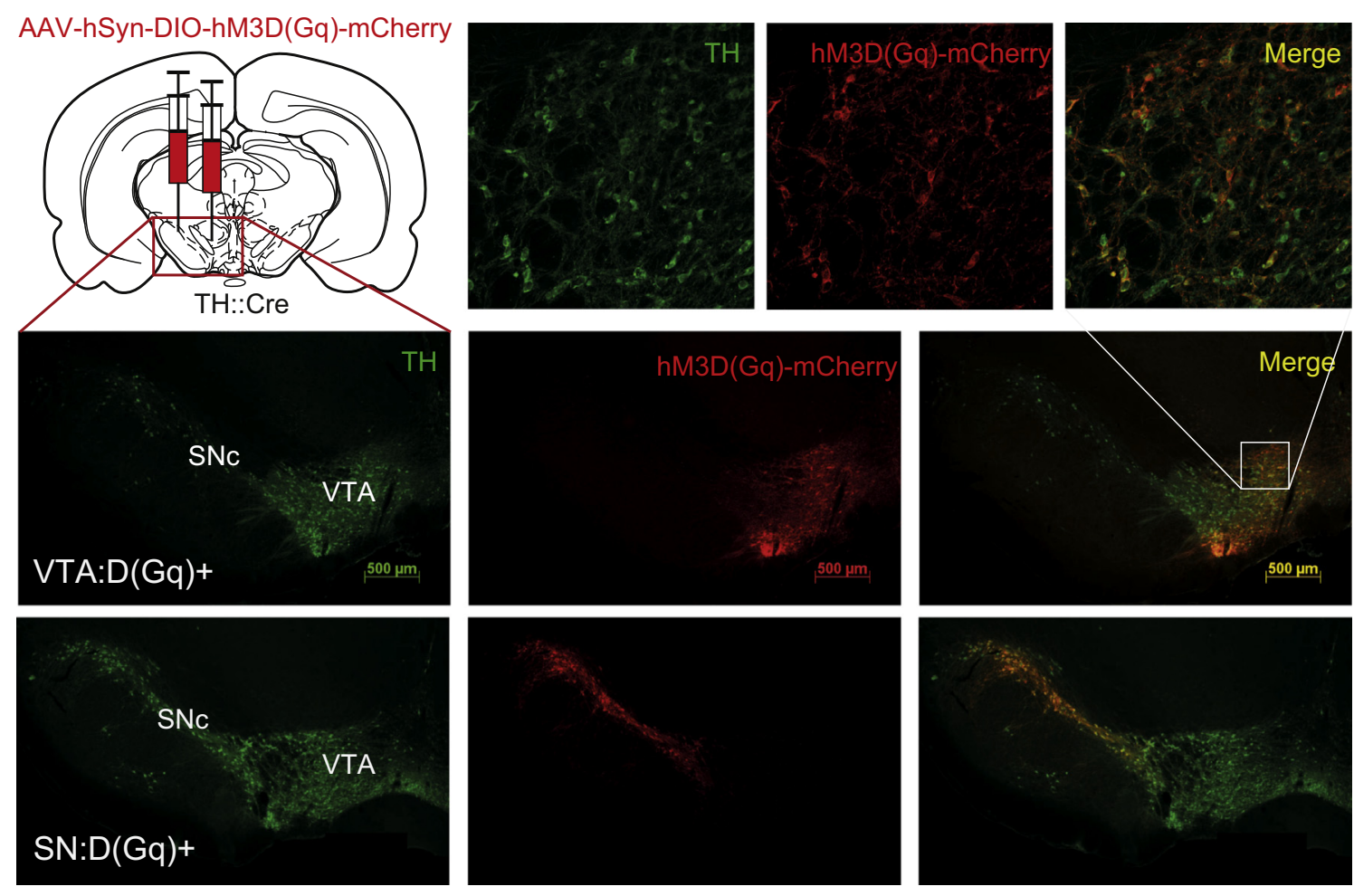

B

Active lever presses

C

Inactive lever presses
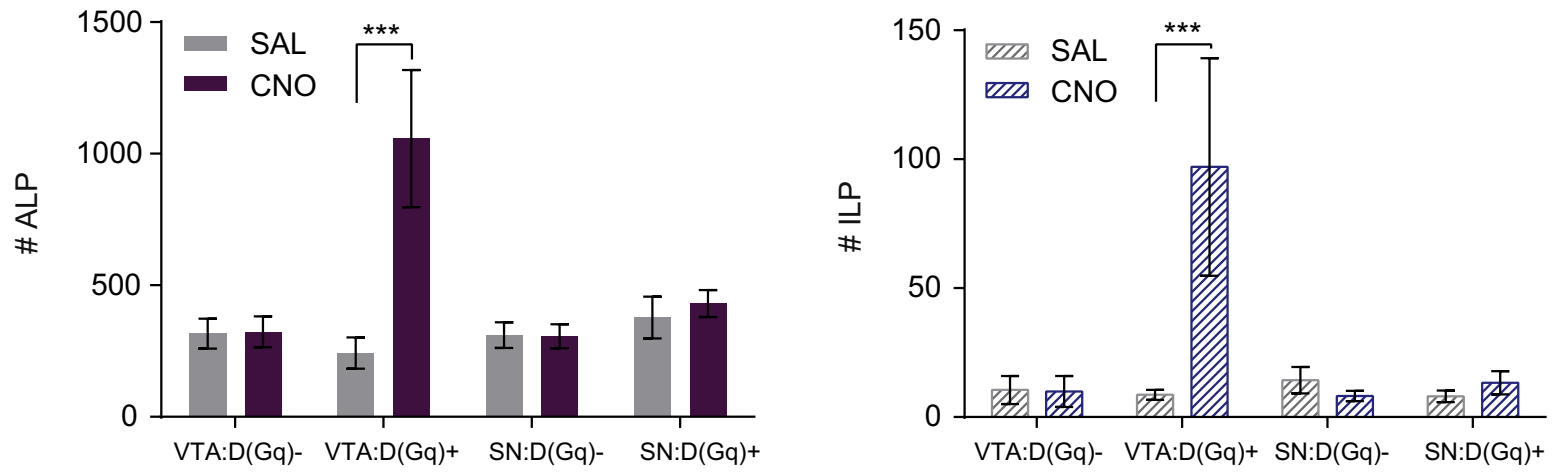

D

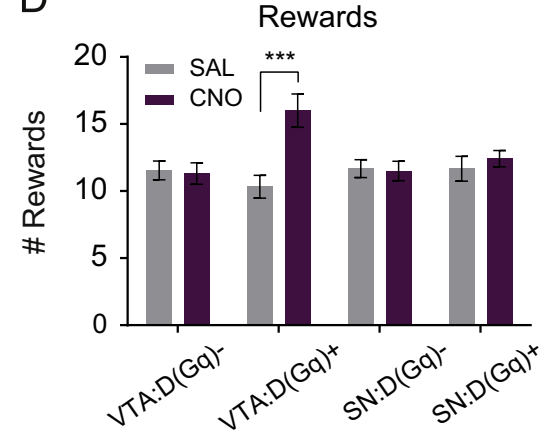

E

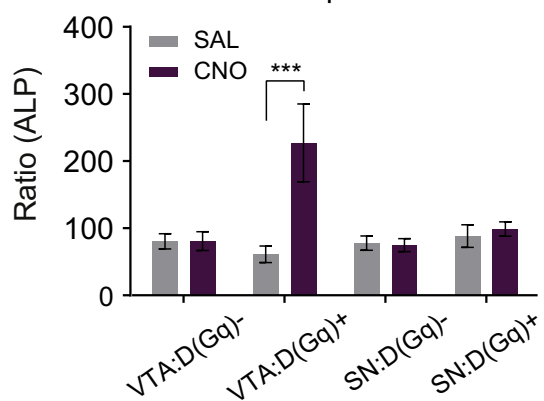

F

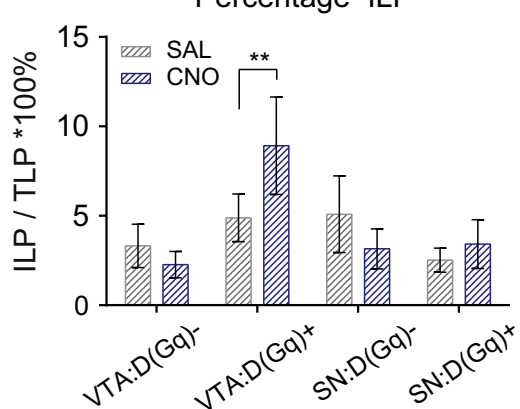


Figure 1 Chemogenetic activation of DA neurons in VTA, but not SNc, increases responding for sucrose under a PR schedule of reinforcement. A) All rats received bilateral injections with Cre-dependent DREADD virus into either VTA or SNc. Representative examples are shown of DREADD expression in DA $(\mathrm{TH}+)$ neurons in VTA or SNc in TH:Cre + rats. B-F) Effects of chemogenetic activation of DA neurons in VTA or SNc on responding for sucrose under PR schedule. In VTA:D(Gq) + rats, CNO treatment increased ALP (B), ILP (C), rewards (D), breakpoint (E), and percentage ILP (F). CNO treatment did not affect performance in SN:D(Gq) + rats or Cre- control groups (VTA:D(Gq)- and SN:D(Gq)-). Data are presented as mean \pm s.e.m. $n=6-12 /$ group. ${ }^{* *} \mathrm{P}<0.01$, ${ }^{* * *} \mathrm{P}<0.001 \mathrm{CNO}$ compared to saline (SAL). ALP: active lever presses; ILP: inactive lever presses; TLP: total lever presses (ALP+ILP).

per group. For follow-up tests on the effects of VTA:D(Gq)+ activation on behaviour, $\mathrm{SN}: \mathrm{D}(\mathrm{Gq})+$ rats as well as $\mathrm{SN}: \mathrm{D}(\mathrm{Gq})$ - controls were excluded from the analysis, since no effects were observed on responding following chemogenetic activation of SNc DA neurons. Comparisons between groups (for reversal test) were made with Mann-Whitney U Test (ALP, ILP), or two sample t-test (\%ALP). \%ALP was compared to $50 \%$ test value with one-sample t-test. Statistical significance was set at $\alpha=0.05$.

\section{Results}

\subsection{Chemogenetic activation of DA neurons in VTA, but not SNc, increases responding for sucrose}

DREADD expression was verified throughout the VTA and SNC in VTA:D(Gq)+ and $S N: D(G q)+$ groups, respectively (Figure $1 \mathrm{~A})$. In the absence of Cre (Cre- control group), no DREADD expression was observed (data not shown). Consistent with earlier studies (Boekhoudt et al., 2017, 2016), DREADD was highly co-localised with TH, i.e. $92 \%$ in the VTA: $D(G q)+$ group (304/332 cells) and $97 \%$ in the $S N: D(G q)+$ group ( $367 / 379$ cells). In the VTA:D $(\mathrm{Gq})+$ group, approximately $40 \%$ of VTA DAergic neurons was found to express DREADD (235/573 cells), compared to nearly $80 \%$ of SNC DA cells in the $S N: D(G q)+$ group $(432 / 548$ cells).

To test whether chemogenetic activation of DA neurons in either the VTA or SNc affected motivational behaviour, responding for sucrose under a PR schedule of reinforcement was tested following treatment with $\mathrm{CNO}$ compared to saline. CNO treatment significantly increased the number of ALP in the VTA:D(Gq) + group, but did not affect performance in the $\mathrm{SN}: \mathrm{D}(\mathrm{Gq})+$ group or Cre- control groups (Figure 1B; Group*Treatment interaction $\mathrm{F}_{3,34}=11.841, \mathrm{P}<0.0005$; post hoc $\mathrm{CNO}$ vs Sal VTA:D(Gq) + P<0.0005; SN:D(Gq)+, VTA:D(Gq)- and $S N: D(G q)-P>0.05)$. CNO treatment also increased ILP in the VTA:D $(G q)+$ group, but not in $S N: D(G q)+$ or Cre- groups (Figure 1C; Group*Treatment interaction $F_{3,34}=11.011$, $\mathrm{P}<0.0005$; post hoc CNO vs Sal VTA:D(Gq) $+\mathrm{P}<0.0005$; SN: $D(G q)+$ and Cre- $P>0.05)$. Consequent to the increase in ALP, CNO-treated VTA:D $(\mathrm{Gq})+$ rats earned more rewards, and reached a higher breakpoint compared to saline treatment (Figure 1D+E; Group*Treatment interaction rewards $F_{3,34}=11.428$, breakpoint $F_{3,34}=11.913$, both $P<0.0005$; post hoc $C N O$ vs saline VTA:D $(G q)+$ both $P<0.0005)$. The percentage ILP was higher following CNO treatment in the VTA:D $(\mathrm{Gq})+$ group (Figure 1F, Group*Treatment interaction $F_{3,34}=3.212, P=0.035$; post hoc CNO vs Sal VTA:D(Gq)+ $P=0.008$ ). Thus, chemogenetic activation of VTA DA neurons significantly increased responding on both the active and inactive lever under a PR schedule of reinforcement, whilst activation of SNC DA neurons had no effect.
Because of the absence of behavioural effects of $\mathrm{CNO}$ treatment in SN:D(Gq) + rats, only VTA:D $(G q)+$ and VTA:D $(\mathrm{Gq})$ - groups were included in subsequent analyses.

\subsection{Increased responding following VTA DA neuron activation is associated with augmented ALP bouts}

To examine which aspects of motivational behaviour underlie the CNO-induced increase in responding in VTA:D(Gq)+ rats, we analysed the animals' ALP patterns over the course of the PR sessions (Figure 2). Completion of a higher ratio requirement (breakpoint) was found to be accompanied by an increased number of ALP bouts (Figure 2A). Following CNO treatment, rats performed more than twice the number of ALP bouts compared to saline conditions (Figure $2 \mathrm{~B}, \mathrm{t}_{8}=-5.768, \mathrm{P}<0.0005$ ). The number of lever presses within a bout or the time between consecutive bouts were similar across increasing ratios, and were not affected by CNO treatment (Fig C-F; ALP per bout $t_{8}=0.208$, $P=0.84$; interval $t_{8}=0.495, P=0.634$ ). Whilst the rats spent more time to complete the higher ratio following CNO treatment (Figure $2 \mathrm{G}-\mathrm{H} ; \mathrm{t}_{8}=-3048, \mathrm{P}=0.016$ ), the overall response rate was not affected (Figure $2 \mathrm{I}-\mathrm{J} ; \mathrm{t}_{8}=-0.213$, $P=0.823$ ). These results indicate that completion of high effort ratios following chemogenetic activation of VTA DA neurons was particularly characterised by an increase in the number of ALP bouts, rather than longer bouts or a faster response rate.

\subsection{Effects of VTA DA neuron activation on responding for sucrose are dependent on effort requirements and lever contingencies, but not sucrose pre-feeding}

Based on these results, we hypothesized that the CNOinduced increase in responding for sucrose in VTA:D $(G q)+$ rats was driven by a continued initiation of reward-seeking actions, i.e. that enhancing the excitability of VTA DA neurons promotes the engagement in motivational behaviour. This effect may be independent of reinforcer value, or even the presence of the reinforcer. To test this, we determined the effects of VTA DA neuron activation on instrumental responding 1) following prior access to the reinforcer; and 2) in the absence of the reinforcer. In addition, we tested whether the increased responding for sucrose was dependent on effort requirements and instrumental contingencies, by determining the effects of VTA DA neuron activation 3) under low effort requirements; and 4) following reversal of the active and inactive lever. 

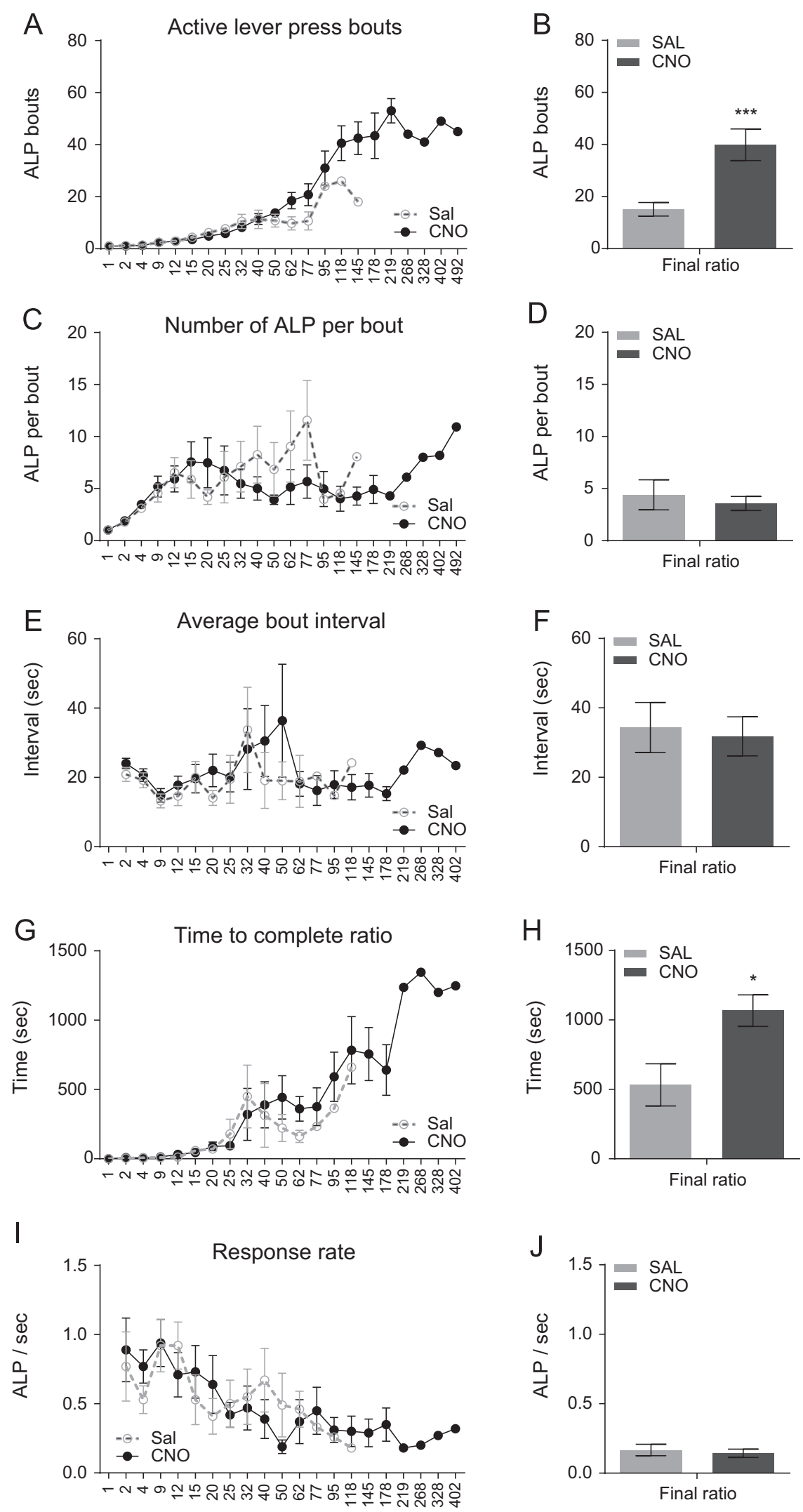

Ratio requirement for next reward (LP)

Figure 2 Effects of VTA DA neuron activation on lever press patterns under PR schedule. Different aspects of lever press behaviour were analysed over the course of the instrumental task, i.e., with progressively increasing lever press requirements to earn the next reward. Left panel shows patterns throughout progressively increasing ratios, whilst right panel shows ALP pattern during the highest ratio achieved. A-B) Number of ALP bouts. C-D) Number of ALP per bout. E-F) Interval between ALP bouts. G-H) Time to complete ratio. I-J) ALP rate. Data are presented as mean \pm s.e.m. $n=9 .{ }^{*} \mathrm{P}<0.05,{ }^{* * *} \mathrm{P}<0.001 \mathrm{CNO}$ compared to saline (SAL). ALP: active lever presses. 


\subsubsection{Prior access to reinforcer}

To determine whether increased responding following VTA DA neuron activation is dependent on reinforcement value, we tested the effect of CNO treatment on responding for sucrose under a PR schedule of reinforcement, following sucrose pre-feeding. First, we established that pre-feeding significantly diminished responding for sucrose (Figure $3 \mathrm{~A}$; main effect of pre-feeding on ALP in saline condition, compared to baseline, $F_{1,19}=55.986, P<0.0005$; no effect on \%ILP $\left.F_{1,19}=0.006, P=0.941\right)$. Next, we found that CNO treatment increased ALP in the VTA:D $(G q)+$ group, irrespective of pre-feeding conditions (Figure 3A; Group*Treatment interaction $\mathrm{F}_{1,20}=17.612, \mathrm{P}<0.0005$; post hoc VTA:D $(\mathrm{Gq})+\mathrm{CNO}$ vs saline $\mathrm{P}<0.0005$, Cre- $\mathrm{P}=0.417)$, but had no significant effect on the percentage ILP (Cre- saline $4.0 \pm 1.8$, CNO 3.9 $\pm 2.7 ;$ VTA:D $(G q)+$ saline $5.2 \pm 2.1$, CNO $12.0 \pm 3.2$; Group*Treatment interaction $F_{1,20}=2.390$, $P=0.138$;). The number of ALP of CNO-treated VTA:D $(G q)$ + rats did not differ between non pre-fed and pre-fed conditions (Figure $3 \mathrm{~A}$; paired samples $\mathrm{t}_{8}=1.124, \mathrm{P}=0.26$ ).

\subsubsection{Absence of reinforcer}

To determine whether $\mathrm{CNO}$-induced enhanced responding was dependent on reward delivery, we tested responding in extinction. In the absence of reinforcement, VTA DA neuron activation enhanced responding. CNO treatment increased ALP in the VTA:D $(G q)+$ group (Figure 3B; Group*Treatment interaction $F_{1,20}=11.301, P=0.003$; post hoc CNO vs Sal VTA: $D(G q)+P=0.002$, Cre- $P=0.396)$, as well as ILP (Group*Treatment interaction $F_{1,20}=16.489, \quad P=0.001$; VTA:D(Gq) + Sal $13.1 \pm 2.4$ vs CNO $54 \pm 11.2$ ILP, $P<0.0005$, Cre- Sal $2.6 \pm 1.8$ vs CNO $17.7 \pm 1.0, P=0.654$ ) and the percentage ILP (Figure 3C; Group*Treatment interaction $F_{1,20}=8.545, P=0.008$; post hoc VTA:D $(G q)+P=0.001$, Cre- $P=0.96)$. Although the increase in responding was modest compared to reinforced responding under the PR schedule $(205 \pm 40 \%$ compared to $579 \pm 180 \%$ of saline) in ALP, respectively, cf. Figures $1 \mathrm{~B}$ to $3 \mathrm{~B}$ ), CNO did increase reward seeking in the absence of reward delivery.

\subsubsection{Effort requirement}

To determine whether the increase in instrumental responding was dependent on the effort requirement, we tested the effects of VTA DA neuron activation under a low effort FR5 schedule of reinforcement. Similar to the PR schedule, sucrose pre-feeding diminished ALP (Figure 3D; main effect of Pre-feeding $\left.F_{1,7}=39.425, P<0.0005\right)$. However, CNO treatment did not significantly affect ALP in either the non-pre-fed or pre-fed condition (Figure 3D; main effect of Treatment $\mathrm{F}_{1,7}=0.191, \mathrm{P}=0.675$; Pre-feeding*Treatment interaction $F_{1,7}=5.302, P=0.055$; non-pre-fed CNO minus Sal $-33.5 \pm 23.7, \quad P=0.201$, pre-fed CNO minus Sal $19.75 \pm 14.1, P=0.203)$. The percentage ILP was marginally affected by pre-feeding and CNO treatment (non-pre-fed saline $0.3 \pm 0.2$, CNO 2.3 \pm 1.1 ; pre-fed saline $3.3 \pm 2.1$, CNO $10.0 \pm 4.0$; Pre-feeding $\mathrm{F}_{1,7}=4.240, \mathrm{P}=0.078$; Treatment $\mathrm{F}_{1,7}=4.865, \mathrm{P}=0.063$; Pre-feeding*Treatment interaction $\left.F_{1,7}=1.228, P=0.304\right)$. Notably, the difference in effects between PR and FR5 schedules could not be attributed to task duration. The effects of CNO on responding under a PR schedule remained the same when only the first 30 minutes of the task were analysed. I.e., CNO treatment increased ALP in VTA:D $(G q)+$ rats (non-pre-fed Sal $209 \pm 57$ vs CNO $356 \pm 97, P=0.035$; pre-fed Sal $62 \pm 10$ vs CNO $227 \pm 73$, $\mathrm{P}=0.03)$, and this did not differ between pre-feeding conditions $(P=0.122)$. Thus, at low ratio requirements, chemogenetic activation of VTA DA neurons did not significantly affect instrumental performance, and did not diminish sensitivity to reduction in reinforcement value.

\subsubsection{Instrumental contingencies}

Finally, to determine whether responding following VTA DA neuron activation was dependent on instrumental contingencies, we tested sensitivity to reversal of the active and inactive lever. If CNO treatment would increase lever pressing irrespective of the outcome, then rats were expected to continue pressing their preferred former active lever. If, however, their behaviour remains flexible and outcome-dependent, the rats were expected to perform more effort, whilst shifting their preference to the new active lever. The animals were tested under a PR schedule of reinforcement, without prior reversal sessions. Under reversed lever contingencies, CNO treatment increased ALP in the VTA:D $(G q)+$ group compared to the Crecontrol group (Figure $3 \mathrm{~F}$ day 1 ; VTA:D $(\mathrm{Gq})+$ vs Cre$Z=-2.562, P=0.009$ ), but did not affect ILP (Figure 3F; VTA: $D(G q)+$ vs Cre- $Z=1.095, P=0.195)$. The VTA:D(Gq)+ rats pressed the (new) active lever more often than the (new) inactive one, whilst Cre- rats showed a preference for the inactive lever (i.e., the former active lever) (Figure 3F; \%ALP VTA:D(Gq) + vs Cre- $\mathrm{t}_{6.14}=4.281, \mathrm{P}=0.005 ; \mathrm{VTA}: \mathrm{D}(\mathrm{Gq})+\% \mathrm{ALP}$ $>50 \% \mathrm{t}_{4}=5.47, \mathrm{P}=0.005$, Cre- \%ALP $<50 \% \mathrm{t}_{5}=-2.65$, $\mathrm{P}=0.045$ ). The preference for the (new) active lever did not persist in VTA:D $(G q)+$ rats during a second session, when all animals were treated with saline. On this second day, both VTA:D(Gq) + and Cre- groups showed no preference for either lever (Figure 3F day 2; \%ALP VTA:D(Gq) + vs Cre- $\mathrm{t}_{9}=0.678$, $P=0.515 ; \% A L P$ vs $50 \%$ VTA: $D(G q)+t_{4}=1.493, P=0.21$, Cre$\left.t_{5}=0.125, P=0.905\right)$, and the groups performed equally (Figure 3F; VTA:D $(\mathrm{Gq})+$ vs Cre- ALP: $Z=-0.274, P=0.829$; ILP: $Z=-1.905, P=0.329)$. Thus, VTA DA neuron activation increased responding under a PR schedule for sucrose, in a manner that is sensitive to changes in instrumental contingencies.

\subsection{ALP bouts during responding for sucrose under PR schedule, following pre-feeding or lever reversal}

To examine whether the increase in ALP bouts following VTA DA neuron activation was also present in modified versions of the PR schedule, we analysed ALP bouts during responding following sucrose pre-feeding or lever reversal. After sucrose pre-feeding, the number of ALP bouts during the breakpoint was increased following CNO treatment compared to saline (Figure 4A, VTA:D $(G q)+$ CNO vs saline $\left.\mathrm{t}_{8}=-4.817, \mathrm{P}=0.001\right)$. During the reversal session, CNOtreated VTA:D $(\mathrm{Gq})+$ rats performed on average 45 ALP bouts during their breakpoint, compared to 11 ALP bouts in the CNO-treated Cre- control group, showing a trend towards a similar effect (Figure $4 \mathrm{~B} ; \mathrm{Z}=-1.776, \mathrm{P}=0.095$ ). Thus, enhanced responding for sucrose under a PR schedule 


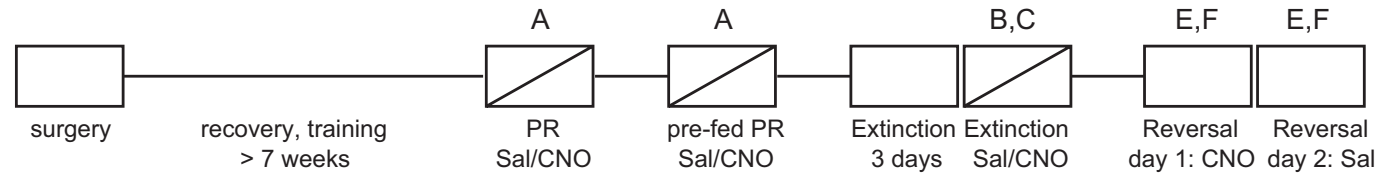

A

PR schedule with pre-feeding Active lever presses

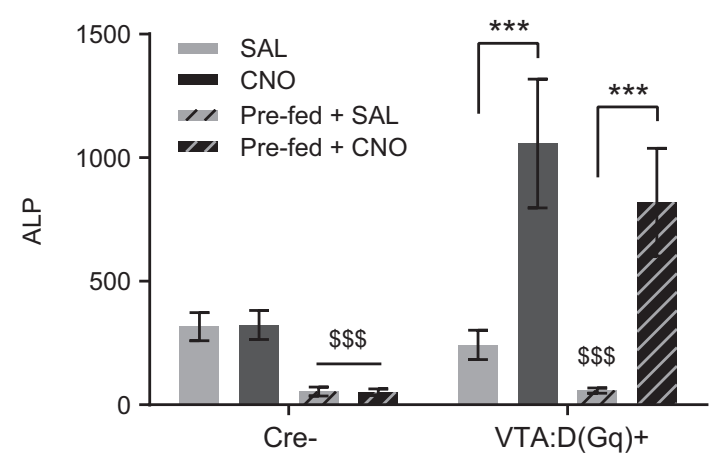

C

Extinction

$\%$ inactive lever presses

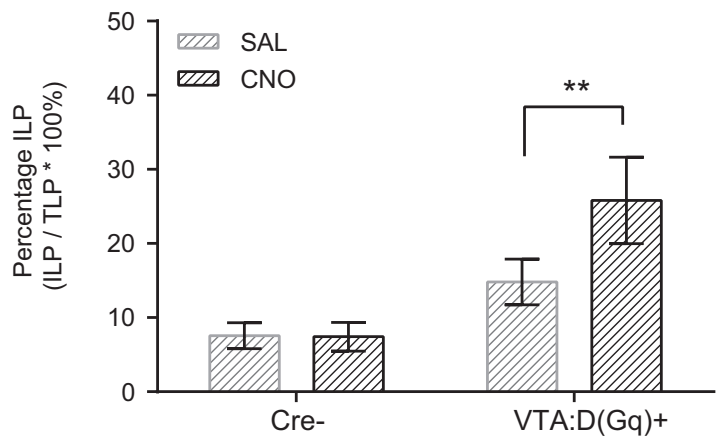

E

Active and inactive lever reversed ALP and ILP

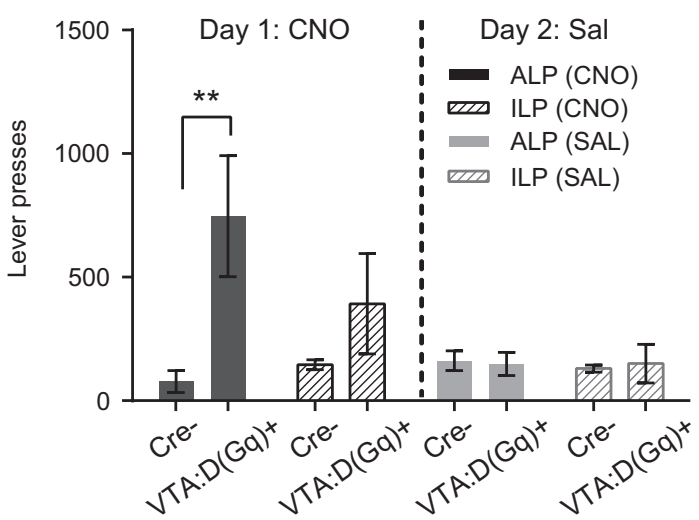

B

Extinction

(non-reinforced) active lever presses

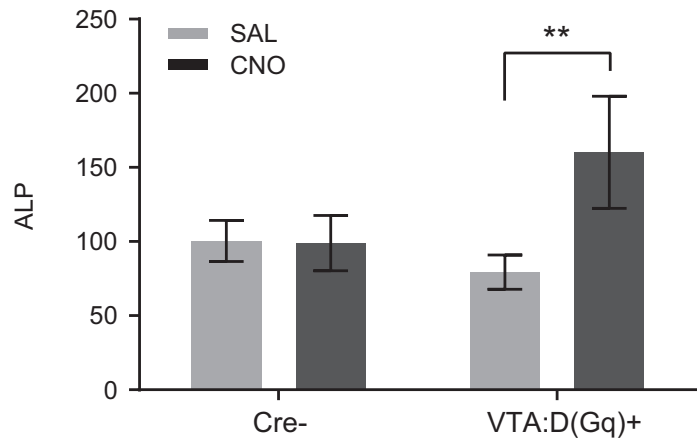

D

Fixed ratio (FR5) Active lever presses

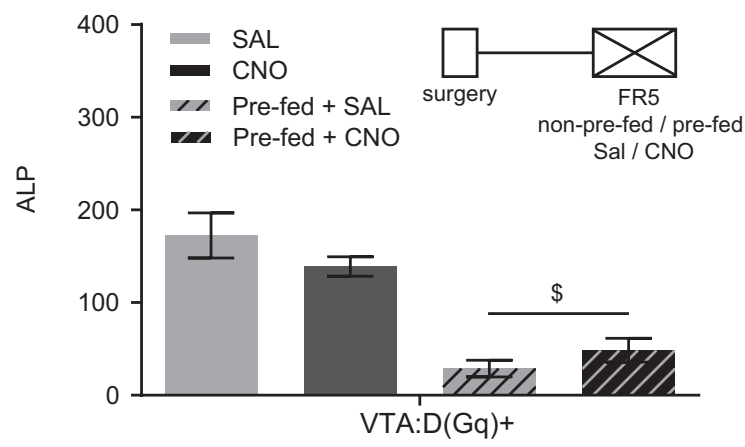

F

Active and inactive lever reversed Percentage ALP

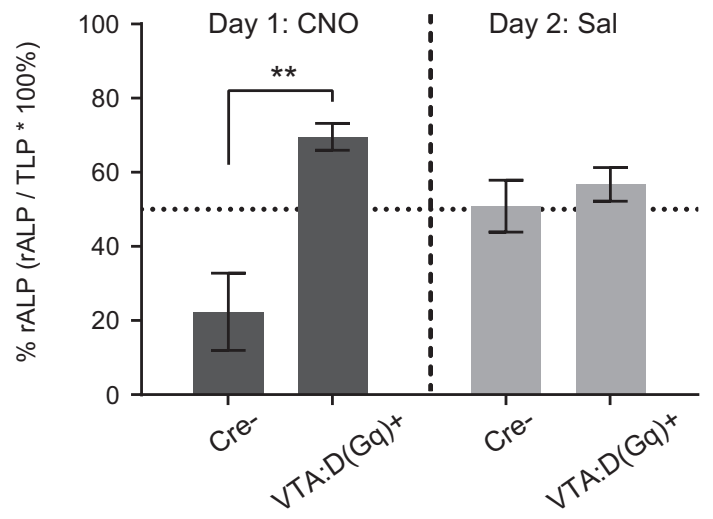


Figure 3 Effects of chemogenetic activation of VTA DA neurons on distinct aspects of motivation. To assess which aspects of motivational behaviour are affected by VTA DA neuronal activation, rats were tested following pre-feeding, in extinction, under a low-effort schedule, and during reversal of the lever contingencies. A) Sucrose pre-feeding decreased ALP under the PR schedule, whilst CNO treatment increased ALP in VTA:D(Gq) + group. B) CNO treatment increased ALP in extinction in VTA:D(Gq)+ group. C) CNO treatment increased \%ILP in extinction in VTA:D(Gq) + group. D) Under an FR5 schedule, pre-feeding decreased ALP, but CNO treatment did not affect performance in VTA:D(Gq) + group. E) CNO increased reversed ALP, but not ILP, in VTA:D(Gq)+ group compared to Cre- control group. F) Percentage of (new) ALP was higher in CNO-treated VTA:D(Gq) + group compared to Cre- control group. On the second day, following SAL treatment, performance did not differ between groups. Data are presented as mean \pm s.e.m. $n=6-12 /$ group $(A), n=9-13 /$ group $(B, C), n=8$ (D), $n=5-6 /$ group $(E, F)$. ${ }^{*} P<0.05,{ }^{* *} P<0.01,{ }^{* * *} P<0.001$ CNO vs Sal; $\$ P<0.05, \$ \$ P<0.001$ main effect of pre-feeding. ALP: active lever presses; ILP: inactive lever presses; TLP: total lever presses (ALP+ILP).

following VTA DA neuron activation was consistently found to be associated with an increase in ALP bouts.

\section{Discussion}

In this study, we sought to unravel the impact of enhancing excitability of midbrain DA neurons on motivational behaviour. Using DREADD technology, we assessed whether chemogenetic activation of DA neurons in either the VTA or SNc is sufficient to increase the motivation to respond for sucrose. In addition, we determined which aspects of motivational behaviour were precisely affected by enhancing DA neuronal excitability.

We found that chemogenetic activation of DA neurons in the VTA, but not SNc, robustly increased responding for sucrose under a PR schedule of reinforcement in rats. This
CNO-induced increase in effort exertion was particularly characterized by an elevated number of ALP bouts. In order to unravel whether the increase in motivational behaviour was caused by a change in reward value, by persistent responding irrespective of reward value, or whether this was the result of the ability to overcome high work requirements, the effect of VTA DA neuron activation was tested after sucrose pre-feeding, in extinction, under a lower ratio requirement, and after reversal of the instrumental contingencies. In summary, our findings show that whereas saline treated rats showed greatly reduced levels of responding when pre-fed with sucrose, when sucrose delivery was omitted, or when action-outcome contingencies switched, CNO treated rats continued to initiate reward-seeking behaviours. This suggests that enhancing excitability of VTA DA neurons stimulates the initiation of
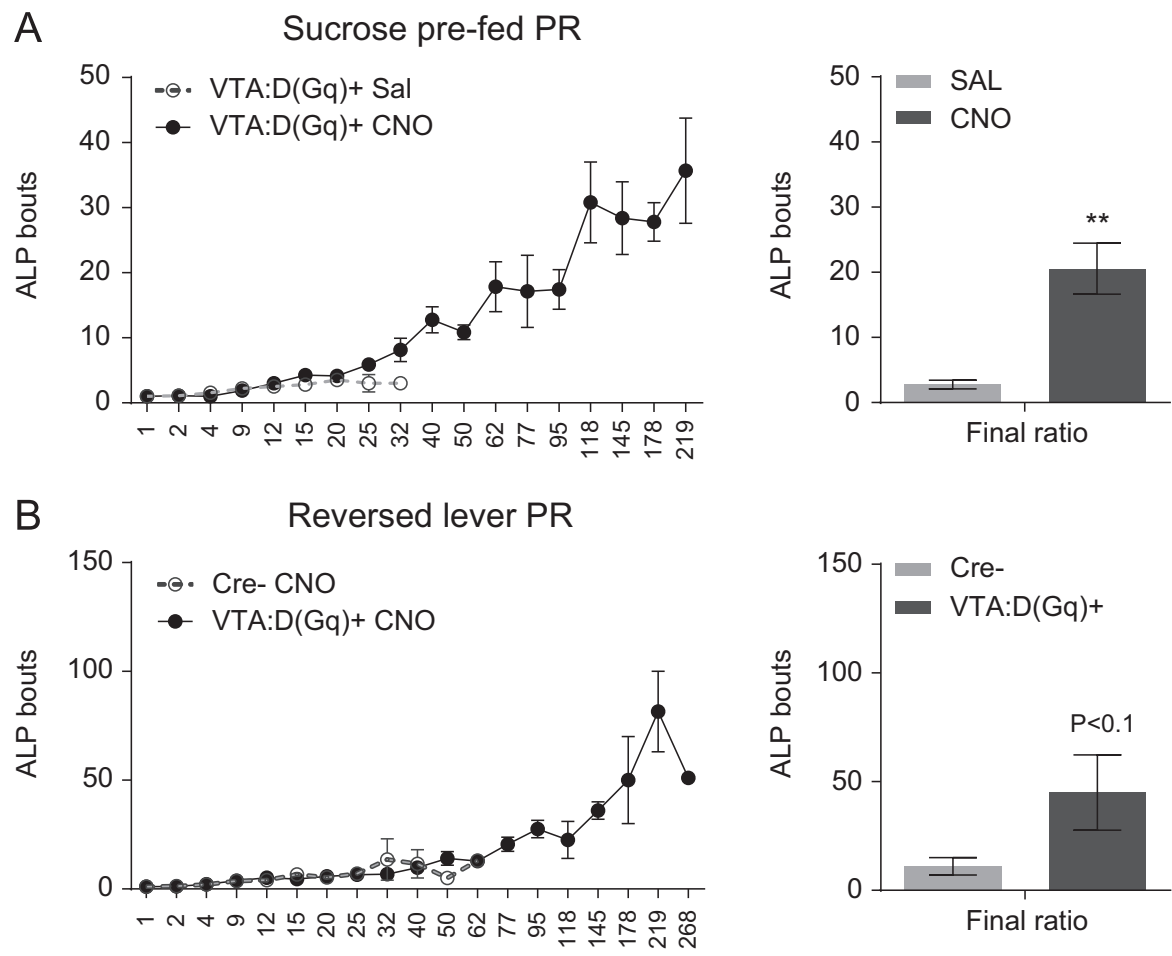

Ratio requirement for next reward (LP)

Figure 4 Effects of VTA DA neuron activation on ALP bouts under a PR schedule of reinforcement, following pre-feeding or lever reversal. Lever press patterns were analysed over the course of progressively increasing ratio requirements. A) Number of ALP bouts following sucrose pre-feeding in VTA:D $(G q)+$ rats, CNO treatment compared to saline. B) Number of ALP bouts following reversal of lever contingencies. VTA:D $(\mathrm{Gq})+$ group compared to Cre- group. $n=9(A), n=5-6 /$ group $(B)$. ${ }^{* *} P<0.01$ CNO compared to Sal. ALP: active lever presses. 
reward-seeking actions, thereby promoting the animal to engage in motivational behaviour, and resulting in increased exertion of effort. This effect was dependent on effort requirements, but appeared to be independent of reinforcement values, or even the presence of the reinforcer.

\subsection{VTA DA neuron activation promotes exertion of effort, even following prior access to reinforcer}

We found VTA DA neuronal activation increased responding for sucrose under progressively increasing ratio requirements, even after sucrose pre-feeding. Whilst pre-feeding potently reduced exertion of effort for sucrose under saline treatment conditions, this effect was no longer observed following chemogenetic activation of VTA DA neurons. This suggests that elevated DA signalling counteracted or overruled the pre-feeding-induced reduction in the value of sucrose. However, at low ratio requirements, i.e., under an FR5 schedule, VTA DA neuron activation did not affect the responding for sucrose following pre-feeding. This supports the notion that homeostatic state and mesolimbic DA activity may affect different aspects of motivational behaviour (Aberman and Salamone, 1999; Narayanan et al., 2010). Whilst satiety (or hunger) may affect the overall incentive value of the reinforcer, VTA DA neuronal activity appears to specifically act on activational aspects of motivation, which are particularly taxed under high effort requirements (Berridge, 2007; Salamone and Correa, 2012). In other words, reward value was not affected by enhanced VTA DA neuronal activity, but rather the effort the animals were prepared to invest in order to obtain the reward.

Thus, responding for (palatable) food in low-effort situations appears to be primarily affected by homeostatic state, whilst responding for food in high-effort situations is highly sensitive to changes in mesolimbic DA signalling. This is clearly represented in our data, showing that under a loweffort FR5 schedule, responding is affected by sucrose prefeeding, but not chemogenetic activation of VTA DA neurons. In contrast, VTA DA neuronal activation increased responding under high-effort requirements, even in a satiated state. These observations are in line with a specific role for mesolimbic DA in sensitivity to work load (Aberman and Salamone, 1999; Salamone et al., 2001). This is consistent with previous studies, showing that NAC DA depletion selectively impaired instrumental performance when ratio requirements were high, whilst leaving performance at low ratio schedules unaffected (Aberman and Salamone, 1999; Ishiwari et al., 2004; Salamone et al., 2001). Our result support this, showing that enhanced VTA DA neuronal activity promotes reward-seeking behaviour despite high response costs. Future studies are warranted to further investigate the mechanisms by which homeostatic state and mesolimbic DA neuronal activity interact to regulate motivational behaviour.

\subsection{VTA DA neuron activation promotes flexible reward-seeking}

Pre-feeding did not affect motivation to respond for sucrose in CNO-treated rats, and these animals also showed enhanced responding in extinction. Moreover, VTA DA neuron activation increased the total number of ILP as well as the percentage of ILP under a PR schedule of reinforcement, and in extinction sessions. An increase in ILP is often considered to be the consequence of a general increase in activity. Previously, we showed that chemogenetic activation of VTA DA neurons indeed induced locomotor hyperactivity (Boekhoudt et al., 2016; Boender et al., 2014), consistent with other studies (Wang et al., 2013). Hence, enhanced behavioural activity is likely to contribute to the observed increase in instrumental responding. However, in the present study, we found that responding under an FR5 schedule of reinforcement was not affected by VTA DA neuron activation, which should have been increased if our manipulation indiscriminately augmented behavioural output. Moreover, we also observed that rats could advantageously adjust their behaviour following VTA DA neuron activation, and switch their lever press preference towards the former inactive lever when action-outcome contingencies were reversed. This indicates that instrumental responding was directed towards obtaining the sucrose reward. Therefore, we argue that increasing VTA DA neuronal excitability does not reduce the goal-directedness of motivational behaviour, but that the increase in responding represents enhanced flexible reward-seeking. Increased ILP may reflect a strategy shift in situations when ALP are not (immediately) reinforced, e.g.: at high ratio requirements, in extinction, or following lever reversal. Thus, chemogenetic activation of VTA DA neurons promotes behavioural activation in a flexible and goal-directed fashion.

\subsection{DA-induced increases motivational behaviour are driven by enhanced action initiation}

To understand in more detail how VTA DA neuronal activation increased responding under a PR schedule, we analysed lever press patterns over the course of progressively increasing ratio requirements. We reasoned that hyperactivity would be reflected in an increased number of presses per bout, more rapid lever press rate, and/or reduced intervals between bouts of lever pressing. However, we observed no difference in these aspects of lever press behaviour between saline and CNO treated sessions. Rather, we found that rats continued to initiate lever pressing under high ratio requirements. This indicates that chemogenetic VTA DA neuronal activation resulted in behavioural activation (in anticipation of a reward).

High breakpoints following VTA DA neuron activation were particularly characterised by an increase in the number of ALP bouts. This effect was consistently observed during responding under a PR schedule, also following sucrose pre-feeding, and a trend was observed during the lever reversal session. This suggests that VTA DA neuronal activation drives motivational behaviour by enhancing the initiation of reward-seeking actions, even when these actions are not immediately reinforced. Indeed, a selective effect on the willingness to repeatedly engage in goaldirected behaviour, in the anticipation of a reward, also explains the effort-dependent effect of VTA DA neuronal activation. 
Recently, it was shown that transient increases in NAC DA levels - representing phasic activity of VTA DA neurons were associated with action initiations during instrumental performance under a PR schedule in rats (Ko and Wanat, 2016). Although this study has also found relationships between DA transients and the number of presses per bout and interval between bouts, our results suggest that these aspects of responding were not directly affected by increased VTA DA neuronal excitability. Together, these findings support a vital role for mesolimbic DA activity in the initiation of reward-anticipated actions (Hamid et al., 2015; Ko and Wanat, 2016; Nicola, 2010; Syed et al., 2016), and provide a neural mechanism for altered sensitivity to work load.

\subsection{No evidence for effects of SNc DA neuron activation on motivational behaviour}

Although it has been suggested that nigrostriatal DA may be involved in motivational processes as well (Ikemoto et al., 2015; Palmiter, 2008; Wise, 2009), we found no effects of chemogenetic activation of SNc DA neurons on responding for sucrose under a PR schedule of reinforcement. To our knowledge, we are the first to directly test the effects of increased activity of SNc DA neurons on incentive motivation. A limited number of studies previously investigated the effects of altered DA signalling in the dorsal striatum (the target site of SNc DA neurons). These studies found that neither lesions of the dorsal striatum, nor overexpression of DA D2 receptors, affected motivation to respond for sucrose in rodents (Eagle et al., 1999; Trifilieff et al., 2013). Pharmacological blockade of DA receptors in the dorsal striatum has been shown to dose-dependently decrease the motivation for cocaine in rats, whereas responding for food under a low ratio schedule was not affected (Veeneman et al., 2012). Interestingly, an earlier study did show that dorsal striatum DA receptor blockade reduced responding for food under a variable interval schedule (Beninger and Ranaldi, 1993). These latter findings are in line with the theory that the nigrostriatal DA pathway is particularly recruited during habit formation and habitual behaviour (Balleine and O'Doherty, 2010). Importantly, in the present study, the rats were tested under ratio schedules, in which (unlike interval schedules, see Dickinson et al., 1983) higher levels of responding result in the delivery of more reinforcers. In other words, behaviour in the present study was likely goal-directed rather than habitual. Future studies should elucidate whether (chemogenetic) activation of SNc DA neurons does affect behaviour during or following habit-formation. Together, these data suggest that SNc DA neuronal activity is not directly involved in the regulation of motivation for palatable food, although future studies are needed to substantiate this.

Importantly, our negative findings on SNc DA neuron activation are unlikely to results from methodological issues. We observed substantial DREADD expression in the $\mathrm{SN}: \mathrm{D}(\mathrm{Gq})+$ group, with twice as many DA neurons expressing DREADD in the SNc compared to VTA in the VTA:D $(G q)+$ group. Furthermore, we previously showed that effects of
$\mathrm{hM} 3 \mathrm{D}(\mathrm{Gq})$ stimulation on neuronal activity in vitro were similar in VTA and SNc DA neurons (Boekhoudt et al., 2016), and that chemogenetic activation of SNC DA neurons increased locomotor activity (Boekhoudt et al., 2016) and impaired attention (Boekhoudt et al., 2017). With respect to these and other negative findings in this study, it should be noted that for all experimental groups and cohorts, anatomical and functional DREADD functionality was affirmed. All virus batches used successfully resulted in DA-specific DREADD expression in both cell bodies and projection sites, as reported previously (Boekhoudt et al., $2017,2016)$. In addition, a low dose of CNO $(0.3 \mathrm{mg} / \mathrm{kg})$ successfully induced behavioural effects in all cohorts. Although higher doses of CNO have been shown to produce certain off-target effects (Maclaren et al., 2016), we observed no differences between $\mathrm{CNO}$ and saline treatment in the Cre- control group (i.e., in the absence of DREADD expression).

\subsection{Enhancing DA neuronal excitability to relieve motivational deficits in psychiatry}

Mesolimbic DA signalling has been identified as a key regulator underlying motivational deficits in psychiatric disorders (Robinson and Berridge, 1993; Salamone et al., 2015; Whitton et al., 2015; Wise, 2004). Major depressive disorder is characterized by a blunted rewardanticipation signal in the NAc, which disrupts motivational processes (Pizzagalli et al., 2009). It has been hypothesized that this attenuated mesolimbic DA response is caused by reduced phasic VTA DA neuronal activity (Whitton et al., 2015). In schizophrenia, aberrant DA neuronal activity has been proposed to account for inappropriate salience processing and motivational deficits (Howes and Kapur, 2009; Maia and Frank, 2016; Winton-Brown et al., 2014). Importantly, subjects suffering from motivational deficits may still be able to experience the pleasure of rewards, yet they are not motivated to initiate actions to obtain them (Chaudhuri and Behan, 2004; Salamone et al., 2016b; Whitton et al., 2015). Our findings indicate that enhanced activity of VTA DA neurons primarily affects reward-anticipated action initiation, which becomes particularly apparent when effort requirements are high. Thus, enhancing VTA DA neuronal excitability might be a promising approach to relieve these symptoms. Recently, it was shown that increased DAergic function could indeed reverse motivational deficits in a rodent model (Soares-Cunha et al., 2016). However, certain challenges must be addressed when adopting this approach in humans. For example, in schizophrenia, enhanced DA neuronal activity is likely to exacerbate psychotic symptoms (Grace, 2015; Howes and Kapur, 2009; Maia and Frank, 2016). Moreover, when considering (chemogenetic) activation of mesolimbic DA neurons as treatment, its addiction potential should be taken into account (Pascoli et al., 2015). Thus, future studies are needed to elucidate which treatment is most appropriate for different types of motivational deficits. 


\subsection{Conclusions}

In this study, we show that chemogenetic activation of VTA DA neurons increased responding for sucrose in rats. Our results indicate that enhancing excitability of VTA DA neurons promotes the initiation of reward-seeking behaviour, and thereby facilitates the exertion of effort. This is in line with previous findings, indicating that mesolimbic DA signalling is necessary for high effort performance (Hart et al., 2014; Nunes et al., 2013). In line with a role in activational (rather than directional) aspects of motivation (Salamone et al., 2016a), we found that responding at both the active and inactive levers was enhanced in the absence of immediate reinforcement, and that increased effort exertion was particularly characterised by a repeated initiation of rewardseeking actions. Together, our findings emphasize that VTA DA neuronal activity acts as a mediator that translates incentive motivation into physical actions (Balleine and O'Doherty, 2010). These findings may have implications for the development of novel treatments for motivational deficits in psychiatric disorders.

\section{Role of funding source}

This project was funded by NeuroBasic, Full4Health, Nudge-IT (FP7KBBE.2013.2.2-01), ZonMW, Netherlands Organisation for Scientific Research: NWO Top Grant and NWO Veni grant.

\section{Contributors}

LB, JWdJ, GvdP, LJMJV and RAHA designed the study. LB, ECW, JHKM and MCML performed the experiments and $L B, E C W$ and JHKM analysed the results. LB, GvdP, LJMJV and RAHA wrote the manuscript.

\section{Conflict of Interest}

The authors declare no conflict of interest.

\section{Acknowledgements}

We kindly thank Bryan Roth and NIMH Drug Supply Program for supplying CNO. We also like to thank Hans Westrik for assistance in data analysis. This project was funded by NeuroBasic, Full4Health, Nudge-IT (FP7-KBBE.2013.2.2-01), ZonMW, Netherlands Organisation for Scientific Research: NWO Top Grant and NWO Veni grant.

\section{References}

Aberman, J.E., Salamone, J.D., 1999. Nucleus accumbens dopamine depletions make rats more sensitive to high ratio requirements but do not impair primary food reinforcement. Neuroscience 92, 545-552. http://dx.doi.org/10.1016/S0306-4522(01)00249-4.

Aberman, J.E., Ward, S.J., Salamone, J.D., 1998. Effects of dopamine antagonists and accumbens dopamine depletions on time-constrained progressive-ratio performance. Pharmacol. Biochem. Behav. 61, 341-348. http://dx.doi.org/10.1016/ S0091-3057(98)00112-9.

Balleine, B.W., O'Doherty, J.P., 2010. Human and rodent homologies in action control: corticostriatal determinants of goal- directed and habitual action. Neuropsychopharmacology 35, 48-69. http://dx.doi.org/10.1038/npp.2009.131.

Bari, A.A., Pierce, R.C., 2005. D1-like and D2 dopamine receptor antagonists administered into the shell subregion of the rat nucleus accumbens decrease cocaine, but not food, reinforcement. Neuroscience 135, 959-968. http://dx.doi.org/10.1016/j. neuroscience.2005.06.048.

Barter, J.W., Li, S., Lu, D., Bartholomew, R. a, Rossi, M. a, Shoemaker, C.T., Salas-Meza, D., Gaidis, E., Yin, H.H., 2015. Beyond reward prediction errors: the role of dopamine in movement kinematics. . Front. Integr. Neurosci. 9, 1-22. http: //dx.doi.org/10.3389/fnint.2015.00039.

Beninger, R.J., Ranaldi, R., 1993. Microinjections of flupenthixol into the caudate-putamen but not the nucleus accumbens, amygdala or frontal cortex of rats produce intra-session declines in food-rewarded operant responding. Behav. Brain Res. 55, 203-212. http://dx.doi.org/10.1016/0166-4328(93)90116-8.

Berridge, K.C., 2007. The debate over dopamine's role in reward: the case for incentive salience. Psychopharmacology (Berl.) 191, 391-431. http: //dx.doi.org/10.1007/s00213-006-0578-x.

Boekhoudt, L., Omrani, A., Luijendijk, M.C.M., Wolterink-Donselaar, I.G., Wijbrans, E.C., van der Plasse, G., Adan, R.A.H., 2016. Chemogenetic activation of dopamine neurons in the ventral tegmental area, but not substantia nigra, induces hyperactivity in rats. Eur. Neuropsychopharmacol. 26, 1784-1793. http://dx.doi. org/10.1016/j.euroneuro.2016.09.003.

Boekhoudt, L., Voets, E.S., Flores-Dourojeanni, J.P., Luijendijk, M. C., Vanderschuren, L.J., Adan, R.A., 2017. Chemogenetic activation of midbrain dopamine neurons affects attention, but not impulsivity, in the five-choice serial reaction time-task in rats. Neuropsychopharmacology 42, 1315-1325. http://dx.doi.org/ 10.1038/npp.2016.235.

Boender, A.J., de Jong, J.W., Boekhoudt, L., Luijendijk, M.C.M., van der Plasse, G., Adan, R.A.H., 2014. Combined use of the canine adenovirus-2 and DREADD-technology to activate specific neural pathways in vivo. PLoS One 9, e95392. http: / /dx.doi.org/ 10.1371/journal.pone.0095392.

Chaudhuri, A., Behan, P.O., 2004. Fatigue in neurological disorders. Lancet 363, 978-988.

de Jong, J.W., Roelofs, T.J.M., Mol, F.M.U., Hillen, A.E.J., Meijboom, K.E., Luijendijk, M.C.M., van der Eerden, H. a M., Garner, K.M., Vanderschuren, L.J.M.J., Adan, R. a H., 2015. Reducing ventral tegmental dopamine D2 receptor expression selectively boosts incentive motivation. Neuropsychopharmacology 40, 2085-2095. http://dx.doi.org/10.1038/npp.2015.60.

Dickinson, A., Nicholas, D.J., Adams, C.D., 1983. The effect of the instrumental training contingency on susceptibility to reinforcer devaluation. Q. J. Exp. Psychol. Sect. B 35, 35-51. http://dx. doi.org/10.1080/14640748308400912.

Eagle, D.M., Humby, T., Dunnett, S.B., Robbins, T.W., 1999. Effects of regional striatal lesions on motor, motivational, and executive aspects of progressive-ratio performance in rats. Behav. Neurosci. 113, 718-731. http://dx. doi.org/10.1037/0735-7044.113.4.718.

Fervaha, G., Foussias, G., Agid, O., Remington, G., 2015. Motivational deficits in early schizophrenia: prevalent, persistent, and key determinants of functional outcome. Schizophr. Res. 166, 9-16. http://dx.doi.org/10.1016/j.schres.2015.04.040.

Fervaha, G., Foussias, G., Takeuchi, H., Agid, O., Remington, G., 2016. Motivational deficits in major depressive disorder: crosssectional and longitudinal relationships with functional impairment and subjective well-being. Compr. Psychiatry 66, 31-38. http://dx.doi.org/10.1016/j.comppsych.2015.12.004.

Grace, A.A., 2015. Dopamine system dysregulation and the pathophysiology of schizophrenia: insights from the methylazoxymethanol acetate model. Biol. Psychiatry, 1-4. http://dx.doi. org/10.1016/j.biopsych.2015.11.007.

Hamid, A.A., Pettibone, J.R., Mabrouk, O.S., Hetrick, V.L., Schmidt, R., Vander Weele, C.M., Kennedy, R.T., Aragona, B.J., Berke, J. 
D., 2015. Mesolimbic dopamine signals the value of work. Nat. Neurosci. 19, 117-126. http://dx.doi.org/10.1038/nn.4173.

Hart, G., Leung, B.K., Balleine, B.W., 2014. Dorsal and ventral streams: the distinct role of striatal subregions in the acquisition and performance of goal-directed actions. Neurobiol. Learn. Mem. 108, 104-118. http://dx.doi.org/10.1016/j. $\mathrm{nlm} .2013 .11 .003$.

Howes, O.D., Kapur, S., 2009. The dopamine hypothesis of schizophrenia: version III-the final common pathway. Schizophr. Bull. 35, 549-562. http://dx.doi.org/10.1093/schbul/sbp006.

Ikemoto, S., Yang, C., Tan, A., 2015. Basal ganglia circuit loops, dopamine and motivation: a review and enquiry. Behav. Brain Res. 290, 17-31. http://dx.doi.org/10.1016/j.bbr.2015.04.018.

Ilango, A., Kesner, A.J., Keller, K.L., Stuber, G.D., Bonci, A., Ikemoto, S., 2014. Similar roles of substantia nigra and ventral tegmental dopamine neurons in reward and aversion. J. Neurosci. 34, 817-822. http://dx.doi.org/10.1523/JNEUROSCI.1703-13.2014.

Ishiwari, K., Weber, S.M., Mingote, S., Correa, M., Salamone, J.D., 2004. Accumbens dopamine and the regulation of effort in foodseeking behavior: modulation of work output by different ratio or force requirements. Behav. Brain Res. 151, 83-91. http://dx. doi.org/10.1016/j.bbr.2003.08.007.

Ko, D., Wanat, M.J., 2016. Phasic dopamine transmission reflects initiation vigor and exerted effort in an action- and regionspecific manner. J. Neurosci. 36, 2202-2211. http://dx.doi.org/ 10.1523/JNEUROSCI.1279-15.2016.

la Fleur, S.E., Vanderschuren, L.J.M.J., Luijendijk, M.C., Kloeze, B. M., Tiesjema, B., Adan, R.A.H., 2007. A reciprocal interaction between food-motivated behavior and diet-induced obesity. Int. J. Obes. (Lond.) 31, 1286-1294. http://dx.doi.org/10.1038/sj. ijo.0803570.

Maclaren, D.A., Browne, R.W., Shaw, J.K., Radhakrishnan, S.K., Khare, P., España, R.A., Clark, S.D., 2016. Clozapine-n-oxide administration produces behavioral effects in Long-Evans rats implications for designing DREADD experiments CNO converts into bioactive compounds in rats (219-16). eNeuro 10. http: //dx.doi.org/10.1523/ENEURO.0219-16.2016.

Maia, T.V., Frank, M.J., 2016. An integrative perspective on the role of dopamine in schizophrenia. Biol. Psychiatry, 1-15. http://dx. doi.org/10.1016/j.biopsych.2016.05.021.

Narayanan, N.S., Guarnieri, D.J., DiLeone, R.J., 2010. Metabolic hormones, dopamine circuits, and feeding. Front. Neuroendocrinol. 31, 104-112. http://dx.doi.org/10.1016/j.yfrne.2009.10.004.

Nicola, S.M., 2010. The flexible approach hypothesis: unification of effort and cue-responding hypotheses for the role of nucleus accumbens dopamine in the activation of reward-seeking behavior. J. Neurosci. 30, 16585-16600. http://dx.doi.org/10.1523/ JNEUROSCI.3958-10.2010.

Nunes, E.J., Randall, P.A., Podurgiel, S., Correa, M., Salamone, J. D., 2013. Nucleus accumbens neurotransmission and effortrelated choice behavior in food motivation: effects of drugs acting on dopamine, adenosine, and muscarinic acetylcholine receptors. Neurosci. Biobehav. Rev. 37, 2015-2025. http://dx. doi.org/10.1016/j.neubiorev.2013.04.002.

Palmiter, R.D., 2008. Dopamine signaling in the dorsal striatum is essential for motivated behaviors: lessons from dopaminedeficient mice. Ann. N. Y. Acad. Sci. 1129, 35-46. http://dx. doi.org/10.1196/annals.1417.003.

Pascoli, V., Terrier, J., Hiver, A., Lüscher, C., 2015. Sufficiency of mesolimbic dopamine neuron stimulation for the progression to addiction. Neuron 88, 1054-1066. http://dx.doi.org/10.1016/j. neuron.2015.10.017.

Peciña, S., Cagniard, B., Berridge, K.C., Aldridge, J.W., Zhuang, X., 2003. Hyperdopaminergic mutant mice have higher "wanting" but not "liking" for sweet rewards. J. Neurosci. 23, 9395-9402. http: / /dx.doi.org/10.1097/00008877-200409000-00094.

Pizzagalli, D.A., Holmes, A.J., Dillon, D.G., Goetz, E.L., Birk, J.L., Bogdan, R., Dougherty, D.D., losifescu, D.V., Rauch, S.L., Fava,
M., 2009. Reduced caudate and nucleus accumbens response to rewards in unmedicated subjects with major depressive disorder. Am. J. Psychiatry 166, 702-710. http://dx.doi.org/ 10.1176/appi.ajp.2008.08081201.Reduced.

Richardson, N.R., Roberts, D.C.S., 1996. Progressive ratio schedules in drug self-administration studies in rats: a method to evaluate reinforcing efficacy. J. Neurosci. Methods 66, 1-11. http://dx. doi.org/10.1016/0165-0270(95)00153-0.

Robinson, T.E., Berridge, K.C., 1993. The neural basis of drug craving: an incentive-sensitization theory of addiction. Brain Res. Rev. 18, 247-291. http://dx.doi.org/10.1016/0165-0173(93)90013-P.

Rossi, M.A., Sukharnikova, T., Hayrapetyan, V.Y., Yang, L., Yin, H. H., 2013. Operant self-stimulation of dopamine neurons in the substantia nigra. PLoS One 8, 1-7. http://dx.doi.org/10.1371/ journal.pone.0065799.

Salamone, J.D., Correa, M., 2012. The mysterious motivational functions of mesolimbic dopamine. Neuron 76, 470-485. http: //dx.doi.org/10.1016/j. neuron.2012.10.021.

Salamone, J.D., Koychev, I., Correa, M., Mcguire, P., 2015. Neurobiological basis of motivational deficits in psychopathology. Eur. Neuropsychopharmacol. 25, 1225-1238. http://dx.doi.org/ 10.1016/j.euroneuro.2014.08.014.

Salamone, J.D., Wisniecki, A., Carlson, B.B., Correa, M., 2001. Nucleus accumbens dopamine depletions make animals highly sensitive to high fixed ratio requirements but do not impair primary food reinforcement. Neuroscience 105, 863-870.

Salamone, J.D., Yohn, S.E., López-Cruz, L., San Miguel, N., Correa, M., 2016a. Activational and effort-related aspects of motivation: neural mechanisms and implications for psychopathology. Brain 139, 1325-1347. http://dx.doi.org/10.1093/ brain/aww050.

Salamone, J.D., Yohn, S.E., López-Cruz, L., San Miguel, N., Correa, M., 2016b. Activational and effort-related aspects of motivation: neural mechanisms and implications for psychopathology. Brain 139, 1325-1347. http://dx.doi.org/10.1093/brain/aww050.

Schultz, W., Dayan, P., Montague, P.R., 1997. A neural substrate of prediction and reward. Science (80-. ) 275, 1593-1599. http: //dx.doi.org/10.1126/science.275.5306.1593.

Soares-Cunha, C., Coimbra, B., David-Pereira, A., Borges, S., Pinto, L., Costa, P., Sousa, N., Rodrigues, A.J., 2016. Activation of D2 dopamine receptor-expressing neurons in the nucleus accumbens increases motivation. Nat. Commun. 7, 11829. http://dx. doi.org/10.1038/ncomms11829.

Syed, E.C.J., Grima, L.L., Magill, P.J., Bogacz, R., Brown, P., Walton, M.E., 2016. Action initiation shapes mesolimbic dopamine encoding of future rewards. Nat. Neurosci. 9, 34-36. http: //dx.doi.org/10.1038/nn.4187.

Trifilieff, P., Feng, B., Urizar, E., Winiger, V., Ward, R.D., Taylor, K. M., Martinez, D., Moore, H., Balsam, P.D., Simpson, E.H., Javitch, J.A., 2013. Increasing dopamine D2 receptor expression in the adult nucleus accumbens enhances motivation. Mol. Psychiatry 18, 1025-1033. http://dx.doi.org/10.1038/mp.2013.57.

Veeneman, M.M.J., Broekhoven, M.H., Damsteegt, R., Vanderschuren, L.J.M.J., 2012. Distinct contributions of dopamine in the dorsolateral striatum and nucleus accumbens shell to the reinforcing properties of cocaine. Neuropsychopharmacology 37, 487-498. http://dx.doi.org/10.1038/npp.2011.209.

Wang, S., Tan, Y., Zhang, J.-E., Luo, M., 2013. Pharmacogenetic activation of midbrain dopaminergic neurons induces hyperactivity. Neurosci. Bull. 29, 517-524. http://dx.doi.org/10.1007/ s12264-013-1327-x.

Whitton, A.E., Treadway, M.T., Pizzagalli, D.A., 2015. Reward processing dysfunction in major depression, bipolar disorder and schizophrenia. Curr. Opin. Psychiatry 28, 7-12. http://dx. doi.org/10.1080/00048670701213211.

Winton-Brown, T.T., Fusar-Poli, P., Ungless, M. a, Howes, O.D., 2014. Dopaminergic basis of salience dysregulation in psychosis. 
Trends Neurosci. 37, 85-94. http://dx.doi.org/10.1016/j. tins.2013.11.003.

Wise, R.A., 2009. Roles for nigrostriatal-not just mesocorticolimbicdopamine in reward and addiction. Trends Neurosci. 32, 517-524. http://dx.doi.org/10.1016/j.tins.2009.06.004.

Wise, R.A., 2004. Dopamine, learning and motivation. Nat. Rev. Neurosci. 5, 483-494. http://dx.doi.org/10.1038/nrn1406.
Witten, I.B., Steinberg, E.E., Lee, S.Y., Davidson, T.J., Zalocusky, K. A., Brodsky, M., Yizhar, O., Cho, S.L., Gong, S., Ramakrishnan, C., Stuber, G.D., Tye, K.M., Janak, P.H., Deisseroth, K., 2011. Recombinase-driver rat lines: tools, techniques, and optogenetic application to dopamine-mediated reinforcement. Neuron 72, 721-733., http://dxdoi.org/10.1016/j. neuron. 2011.10.028. 